\title{
Effect of different levels of soil salinity on rice seeds blooming, seed thickness and storage level (in the case of Uzbekistan)
}

\author{
Rikhsivoy Tellyaev ${ }^{1, *}$, Nematulla Khudaybergenov ${ }^{1}$, and Bakhtiyorjon Khodirov ${ }^{2}$ \\ ${ }^{1}$ Tashkent State Agrarian University, Universitetskaya str., 2, 100140, Tashkent, Uzbekistan \\ ${ }^{2}$ Rice Scientific Research Institute, Tashkent, Uzbekistan
}

\begin{abstract}
In this research, 25 species from the gene pool of plant genetic resources of the Rice Research Institute based on the characteristics of the varieties and 9 high-quality yields that can be grown in different and highly saline conditions, regionalized varieties were selected. Obviously, seed germination, seedling thickness and pre-harvest storage performance of those varieties were studied. Further development of rice in different saline conditions, efficient use of natural and other resources, increase of productivity and its quality was researched. In the experiment, in strongly saline soils, in the 4 th variant with $\mathrm{Cl}$ ion $0.1-0.2 \%$, the germination rate was $10.1-34.9 \%$ in early ripening varieties of rice, $17.8-25.6 \%$ in medium ripening varieties, $11.6-23.0 \%$ in late ripening varieties. However, in the 5 th variant of the very strongly saline experiment, where the $\mathrm{Cl}$ ion content in the soil was higher than $2.0 \%$, the seed germination in early ripening varieties of rice was $0.0-32.9 \%, 0.0-11.7 \%$ and $0-12.3 \%$ in middle ripening, and in late ripening varieties, respectively.
\end{abstract}

\section{Introduction}

Today, 835 million hectares of weak, moderate and strongly saline areas are available. 73 million hectares has referenced to the African continent, followed by 444 million hectares to Asian countries (Australia, Pacific basins, etc.), 80 million hectares to European countries, 112 million hectares to the Latin American continent, 106 million hectares to the eastern part of the world and 20 million hectares to the South American continent $[1,4-6]$. Rice is one of the most important cereal crops in the world, ranking second in the world in terms of area under cultivation and first in terms of productivity [7-9]. In 2020, it was planted in 155 million hectares around the world, accounted for 751.9 million tons of rice. Productivity could have been higher, but rice is grown in $53.2 \%$ saline areas of Asian countries (Australia, Pacific basins, etc.), 13.4\% in Latin America, 12.7\% in the Eastern regions of the world, $9.4 \%$ in Europe, $8.8 \%$ in Africa and $2.5 \%$ saline areas in South America [11-13].

It is important to conduct scientific research on the development and improvement of saline lands in the country, the efficient use of natural resources, the development of rice

\footnotetext{
*Corresponding author: rixsivoy.tillayev@yandex.com
} 
growing, the further strengthening of the ecological situation, food security [2-5, 9]. Today, the continuous development of agricultural production, further strengthening of food security, efficient use of irrigated lands, including saline lands and waters, creation, selection of new varieties of salt-resistant agricultural crops adapted to local soil, climate and environmental conditions, resource-saving modern technologies are being done towards development of grain and rice in Uzbekistan [1]. In this regard, the improvement of rice cultivation technology in different and highly saline soils, the selection of early, middle and late varieties of rice, which can produce in such conditions are very important task for scientists. Many foreign and local scientists have conducted research on the impact of different salinity and germination of rice seeds on soils with different salinity levels [8], seedling thickness and pre-harvest storage of seedlings. For example, P.S.Erygina, N.S.Tur, N.V.Ostapenko, O.A.Doseeva, S.Medunov, N.Ogurtsov, E.K Lutsenko, E.A Marushko, N.V Kononenko, T.G Leonova, T.V.Ivanov, V.K. Sorokin, G. Beatriz, N. Bernstein have conducted scientific research in the field of grain and rice [4-6]. In Uzbekistan, Q. Urazmetov, M.M. Mamatov, R.Sh. Tillaev, M.A. Ergashev, and B.G. Kadirov have researched salinity resistance of competitive high-yielding rice varieties [5].

One of the factors required for the germination of rice seeds in saline soils had a negative effect on osmotic pressure. In non-saline conditions, the osmotic pressure of seeds during germination was 6-10 atm and the seeds germinated in 3-8 days. In saline conditions, it was 5 atm and the seeds germinated in 8-9 days. Of course, these disadvantages in seed germination had led to a decline in rice yields. It was stated that a $2 \%$ solution of FC in strongly saline soils led to a decrease in seed germination rate and root length and mass $[3-4,11]$. It was not recommended to use this FC drug in non-saline soils. This drug only activated the initial growth processes of the root in saline soils with $\mathrm{NaCl}$ salt [8]. It was mentioned that with increasing salt and decreasing moisture levels, the water holding capacity of the soil increases. As the level of soil salinity increases, the osmotic pressure of the soil increases with the swelling power of the plant. Therefore, water consumption by the plant deteriorates. The result is a condition called "physiological dryness." In this case, despite the fact that the soil has enough moisture, the plant cannot consume enough water [19-21, 27]. As a result, the living conditions of the plant slow down, development slows down and yields are lost [8, 10]. According to Norqulov [5], the first signs of damage caused by salinity were: (1) late germination of seeds; (2) uneven growth or developmental delay [3,7].

Thicker sowing of seeds increases the yield to some extent. In the experiments, the seedlings were relatively thick, and the highest yield was 63.7 tons/ha in the areas sown with 6 million seeds per hectare. In the conditions of Uzbekistan, when 5-7.5 million pieces of rice are planted per hectare, that is, $250-350$ bushes and $450-500$ stalks per $1 \mathrm{~m}^{2}$ before harvest, and a rich harvest of rice can be obtained [4-7, 12]. It is extremely important to have an optimal amount of plant per hectare of rice area. It is known that in all crop types, the field germination of the seed is always lower than the laboratory germination. Field germination of seeds depends on seed quality, soil and agronomic conditions, environmental factors. The field germination of cereals is $65-85 \%$. The higher the germination energy of the seeds, the higher the laboratory germination, the higher the germination capacity, the higher the field germination of the seeds [10-11]. Large seeds have high field germination. Field fertility can vary from $17 \%$ to $80 \%$ depending on environmental and agrotechnical factors $[3-5,12]$. It can be concluded that no scientific and practical work has been carried out in our country, such as the selection and separation of salt-tolerant varieties of rice, their cultivation in different and different saline conditions and soils. Therefore, this research was aimed at 1) targeted selection and isolation of rice varieties from the gene pool of plant genetic resources based on their characteristics; 2) to determine the effect of different and highly saline soil environment on the germination of 
seeds of early, middle and late rice varieties in the laboratory and in field conditions; 3 ) to determine the effect of different and varying salinity soils on seedling thickness and preharvest storage of early, middle and late rice varieties; and 4) to distinguish and produce early, medium and late rice varieties according to their resistance to the type and level of salinity.

\section{Materials and methods}

The research was conducted in the experimental fields of the Rice Research Institute during 2009-2011.The Rice Research Institute is located in the south-eastern part of the Tashkent region, in the Chirchik oasis, $15 \mathrm{~km}$ from Tashkent, on the left bank of the Chirchik River. Early ripening "Nukus-2", "Navbahor", "Sanam", medium ripening "Avangard", "Iskandar", "Ilgor", late ripening "UzROS 7-13", "Lazurny" "Mustaqillik" varieties were selected for the experiment.

\subsection{Climatic conditions}

According to 2009-2011 data from the Tuyaboguz meteorological station, the average air temperature in April-May was $16.5-22.5^{\circ} \mathrm{C}$. The relative humidity was around $47-76 \%$ on average during these months.

\subsection{Soil conditions}

1-variant. Non-saline, $\mathrm{Cl}$ ion less than $0.01 \%, \mathrm{SO}_{4}$ ion less than $0.3 \%$, moderate $(\mathrm{RN}-7$ 7.2), meadow-swamp and light gray soils. 2-variant.weakly chlorinated saline, $\mathrm{Cl}$ ion 0.01 $-0.03 \%$ in the soil. 3-variant.moderately chlorinated saline, $\mathrm{Cl}$ ion $0.03-0.1 \%$ in the soil. 4-variant.strongly chlorinated saline, $\mathrm{Cl}$ ion $0.1-0.2 \%$ in the soil. 5-variant.very strongly chlorinated saline, $\mathrm{Cl}$ ion content in the soil is higher than $0.2 \%$. 6-variant.weakly sulfate saline, $\mathrm{SO}_{4}$ ion content in the soil is $0.3-1.0 \%$. 7-variant.saline, moderately sulfated soil, containing $\mathrm{SO}_{4}$ ions 1.0 - 2.0\%. 8-variant.strongly sulfated saline, $\mathrm{SO}_{4}$ ion content in the soil is $2.0-3.0 \%$. 9-variant.very strong sulfate salinity, $\mathrm{SO}_{4}$ ion content in the soil is higher than $3.0 \%$. Elite generation seeds of rice were sown as the main crop, and the experiment was carried out in 9 variants, 4 replicates, 2 varieties, chlorinated and sulfated saline medium. In all variants, rice was planted at the same time, in the second decade of May, which was considered the most favorable for this region.

Placement of laboratory, lysimetric and field experiments in scientific research, calculations, observations were performed using "Methodological manual of the State Commission for Variety Testing of Agricultural Crops" [5] and "Methods of conducting field experiments" [4,8]. Analysis of plant and soil sampling and study of chemical composition was done using "Methods of agrochemical analysis of soil and plants" [6], "accelerated method of assessing samples of rice for resistance to soil salinity" to assess the salt resistance of rice "[3]. The degree of pre-harvest preservation of planted rice plants was calculated by counting the number of seedlings during the full ripening period of the stalk. The method of dispersion analysis was used in mathematical analysis of rice grain yield [2].

\section{Results and discussion}

The results showed that Seeds of early, middle and late maturing local, regionalized varieties of rice were monitored to determine their fertility in laboratory conditions in 
different and highly saline aquatic environments. It was found that fertility of the rice variety in unsalted water $\mathrm{Cl}$ ion was less than $0.01 \%, \mathrm{SO}_{4}$ ion was less than $0.3 \%$. In the first variant, the germination rate of seeds of all rice varieties was $94.8-96.7 \%$. In the second variant, where the weakly saline $\mathrm{Cl}$ ion in the experiment was $0.01-0.03 \%$, the germination rate of seeds was 83.4-94.6\% in early ripening rice varieties, such as Nukus-2 St, Sanam, Guljahon, Sharma (Russia) and "Navbahor". However, the middle-aged "Avangard St", "Iskandar", "Ilgor", "Istiqbol", "Tantana" and other varieties were accounted for 84.1-90.3\%, and the late-ripening "Uzros 7-13 St", "Lazurnyy", "Mustaqillik" and "Tarona" had 84.3-90.8\% of germination rate. In the 3rd variant of the experiment with an average salinity $\mathrm{Cl}$ ion of $0.03-0.1 \%$, the rate of germination was 58.1 $71.7 \%$ in early ripening varieties of rice, followed by $56.4-66.2 \%$ in medium-ripening varieties, and $53.1-62.7 \%$ in late ripening varieties. However, it was $26.3-48.7 \%$ in early ripening varieties, $20.7-39.7 \%$ in medium ripening varieties, $13.3-34.9 \%$ in late ripening varieties in the 4 th variant with high salinity $\mathrm{Cl}$ ion $0.1-0.2 \%$ (Table 1 ).

The 8th variant of the experiment with high salinity, $\mathrm{SO}_{4}$ ion with $0.2-3.0 \%$, the germination of rice seeds was $28.9-57.0 \%$ in early ripening varieties, followed by 21.9 $43.4 \%$ in medium ripening varieties, and $15.8-38.0 \%$ in late ripening varieties. When the high salinity variant 9 with a $\mathrm{SO}_{4}$ ion was higher than $3.0 \%$, the seed germination of earlymaturing varieties of rice was $5.8-41.4 \%$, it was $2.9-22.7 \%$ in medium-ripe varieties, and it was $0.0-10.3 \%$ in late-ripening varieties (Table 1). The results showed that the amount of seed germination decreased as the salinity levels increased, regardless of the rice varieties and growing seasons. Seeds of early rice varieties germinated more than seeds of medium and late varieties (Figure 1). Especially in conditions of very high salinity, the seeds of late rice varieties did not germinate at all. According the experiment, only the seeds of early ripening "Navbahor" and "Nukus-2" germinated by $25.7-38.3 \%$ in highly saline environments with chloride ion, and the germinated rate was $29.7-41.4 \%$ in highly saline environments with sulfate ions (Fig. 1 and Table 1).

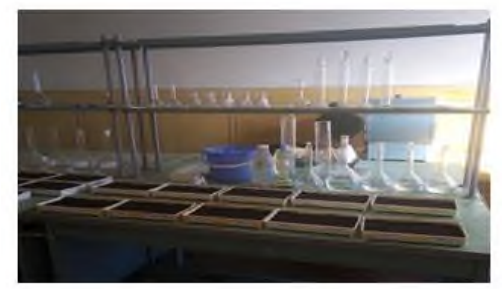

A

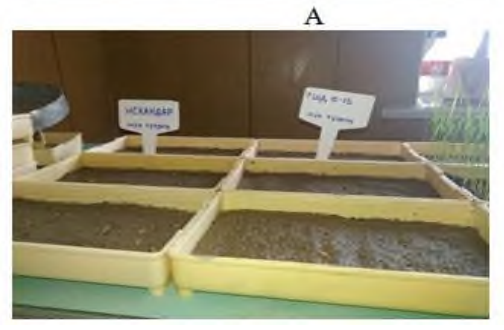

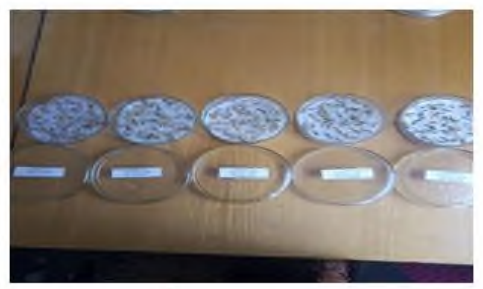

B

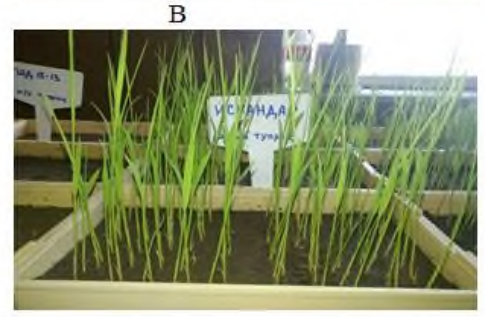

Fig. 1. Study of the process of germination of seeds of rice varieties at different levels of salinity in the laboratory. 
Table 1. The effect of different levels of salinity on the germination of seeds of rice varieties in the laboratory (2009-2011).

\begin{tabular}{|c|c|c|c|c|c|c|c|c|c|c|}
\hline & Variants & 1 control & 2 & 3 & 4 & 5 & 6 & 7 & 8 & 9 \\
\hline \multicolumn{2}{|c|}{ Salinity rate, $\%$} & $\begin{array}{c}\text { Cl ion } 0.01 \\
\%, \\
\mathrm{SO}_{4} \text { ion } \\
\text { less than } \\
0.3 \%\end{array}$ & $\begin{array}{c}\text { Cl } \\
\text { ion } \\
0.01 \\
- \\
0.03 \\
\%\end{array}$ & $\begin{array}{c}\text { Cl } \\
\text { ion } \\
0.03 \\
- \\
0.1 \%\end{array}$ & $\begin{array}{c}\text { Cl } \\
\text { ion } \\
0.1- \\
0.2 \%\end{array}$ & $\begin{array}{c}\text { Cl ion } \\
\text { higher } \\
\text { than } \\
0.2 \%\end{array}$ & $\begin{array}{c}\mathrm{SO}_{4} \\
\text { ion } \\
0.3- \\
1.0 \%\end{array}$ & $\begin{array}{c}\mathrm{SO}_{4} \\
\text { ion } \\
1,0- \\
2.0 \%\end{array}$ & $\begin{array}{c}\mathrm{SO}_{4} \\
\text { ion } \\
2.0- \\
3.0 \% \\
.\end{array}$ & $\begin{array}{c}\mathrm{SO}_{4} \\
\text { ion } \\
\text { highe } \\
\text { r } \\
\text { than } \\
3.0 \%\end{array}$ \\
\hline \multicolumn{11}{|c|}{ Name of varieties } \\
\hline 1 & Nukus-2 St & 96.1 & 91.4 & 69.3 & 45.1 & 25.7 & 94.3 & 73.6 & 54.1 & 29.7 \\
\hline 2 & Sanam & 96.6 & 88.9 & 65.7 & 42.8 & 21.3 & 91.0 & 68.2 & 44.0 & 22.8 \\
\hline 3 & Gulzor & 95.7 & 86.8 & 61.1 & 39.9 & 13.9 & 91.0 & 63.7 & 42.7 & 16.0 \\
\hline 4 & Jaykhun & 95.4 & 86.1 & 60.4 & 41.1 & 11.0 & 89.9 & 61.9 & 43.4 & 14.1 \\
\hline 5 & Arpa-sholi & 95.8 & 83.4 & 58.1 & 35.6 & 8.4 & 85.1 & 69.7 & 38.1 & 10.9 \\
\hline 6 & Nukus -70 & 96.2 & 85.7 & 59.8 & 38.8 & 14.6 & 90.6 & 61.0 & 39.9 & 12.3 \\
\hline 7 & Navbahor & 96.4 & 94.6 & 71.7 & 48.7 & 38.3 & 95.9 & 74.0 & 57.0 & 41.4 \\
\hline 8 & Guljahon & 96.2 & 89.3 & 67.3 & 41.5 & 15.4 & 90.7 & 69.2 & 45.3 & 18.9 \\
\hline 9 & Sitora & 95.3 & 86.5 & 60.7 & 37.6 & 14.7 & 88.3 & 63.1 & 31.1 & 17.1 \\
\hline 10 & Sharma (Russia) & 95.2 & 90.2 & 68.5 & 43.4 & 18.3 & 92.6 & 70.3 & 47.6 & 22.6 \\
\hline 11 & Novator (Russia) & 96.3 & 85.9 & 58.4 & 26.3 & 3.5 & 86.3 & 59.0 & 28.9 & 5.8 \\
\hline 12 & Avangart St & 96.5 & 87.5 & 66.2 & 33.8 & 1.8 & 88.2 & 68.7 & 36.1 & 4.0 \\
\hline 13 & Iskandar & 96.3 & 90.3 & 65.9 & 39.7 & 18.1 & 92.7 & 68.2 & 43.4 & 22.7 \\
\hline 14 & Ilgor & 96.7 & 88.1 & 63.7 & 35.5 & 1.7 & 88.9 & 65.0 & 38.0 & 4.5 \\
\hline 15 & Akhmadsholi & 95.8 & 85.4 & 60.3 & 23.4 & 7.1 & 86.0 & 61.5 & 25.2 & 9.9 \\
\hline 16 & Tursunboy & 95.4 & 84.1 & 59.1 & 21.8 & 1.3 & 85.1 & 60.9 & 24.3 & 2.9 \\
\hline 17 & Istiqbol & 95.5 & 84.7 & 59.7 & 21.6 & 4.8 & 85.2 & 60.4 & 23.9 & 6.0 \\
\hline 18 & Tolmas & 94.8 & 85.3 & 58.2 & 22.5 & 1.3 & 87.1 & 59.3 & 25.0 & 3.1 \\
\hline 19 & Tantana & 95.7 & 84.9 & 56.4 & 20.7 & 3.5 & 85.0 & 57.8 & 21.9 & 5.7 \\
\hline 20 & Uzros 7-13 St & 96.4 & 88.3 & 59.3 & 26.1 & 0.0 & 89.7 & 61.1 & 27.9 & 0.0 \\
\hline 21 & Lazurny & 96.1 & 90.8 & 62.7 & 34.9 & 17.1 & 92.1 & 65.1 & 38.0 & 20.3 \\
\hline 22 & Mustaqillik & 96.7 & 88.5 & 59.8 & 29.3 & 0.0 & 88.8 & 60.3 & 32.6 & 0.0 \\
\hline 23 & Marvarid & 95.4 & 85.1 & 54.0 & 17.1 & 0.0 & 85.9 & 55.7 & 19.9 & 0.0 \\
\hline 24 & Tarona & 96.6 & 84.3 & 54.9 & 15.4 & 0.0 & 85.1 & 56.1 & 17.0 & 0.0 \\
\hline 25 & Istiqlol & 95.3 & 84.7 & 53.1 & 13.3 & 0.0 & 84.9 & 55.6 & 15.8 & 0.0 \\
\hline & $\mathrm{EKF}_{05} \%$ & 4.3 & 3.9 & 3.4 & 3.1 & 2.9 & 4.1 & 3.8 & 3.3 & 3.0 \\
\hline
\end{tabular}

EKF 05 average $3.5 \%$

In our experiments, it was found that the seeds of rice varieties were not salted when they were studied in laboratory conditions in different and degree-saline soils, that was, in the soil content $\mathrm{Cl}$ Ion was less than $0.01 \%$, in the $\mathrm{SO}_{4}$ ion less than $0.3 \%$, in the 1-th variant the fertility of rice seeds was $43,2-51,5 \%$. In the weakly saline soils in the experiment, the $\mathrm{Cl}$ ion was $0.01-0.03 \%$ in the $2 \mathrm{nd}$ variant, which accounted for 41.1 $48.8 \%$ of germination rate in early-maturing varieties of rice, $41.4-46.1 \%$, in medium-ripe varieties and $41.8-45.9 \%$ in late-maturing varieties. In the experiment, in strongly saline soils, in the 4th variant with $\mathrm{Cl}$ ion $0.1-0.2 \%$, the germination rate was $10.1-34.9 \%$ in early ripening varieties of rice, $17.8-25.6 \%$ in medium ripening varieties, $11.6-23.0 \%$ in late ripening varieties. However, in the 5 th variant of the very strongly saline experiment, where the $\mathrm{Cl}$ ion content in the soil was higher than $2.0 \%$, the seed germination in early ripening varieties of rice was $0.0-32.9 \%, 0.0-11.7 \%$ and $0-12.3 \%$ in middle ripening, and in late ripening varieties, respectively. In the 9th variant of very strongly saline soils with SO4 ion content higher than $3.0 \%$, the seed germination of early maturing varieties of rice was $0.0-33.8 \%$, followed by $0.0-15.0 \%$ in medium-ripe varieties, and $0.0 \%-17.1 \%$ in lateripening varieties. In the study, the seeds of all varieties in laboratory conditions in nonsaline aquatic environment was germinated by $94.8-96.7 \%$, and it was $43.2-51.5 \%$ in nonsaline soil conditions, that was low by $51.6-45.2 \%$ compared to laboratory conditions (Table 2). 
These correlations were repeated even when the salinity of the soil was low, that was, the germination of rice seeds in wet conditions was high $83.4-91.4 \%$, in soil conditions, the germination of seeds was low with $41.1-48.8 \%$, and the germination was less by 22.3 $42.6 \%$ compared to the laboratory conditions. However, as the salinity level increased, the germination rate of rice seeds was very close to each other in both water and soil conditions and no significant differences were observed. Rice seeds that germinated under strong and very strongly saline environments were not able to germinate at all under soil conditions (Table 2).

Table 2. Influence of saline soils of different degrees on germination of seeds of rice varieties in laboratory conditions (2009-2011 years).

\begin{tabular}{|c|c|c|c|c|c|c|c|c|c|c|}
\hline \multicolumn{2}{|c|}{ Variants } & $\begin{array}{c}1 \\
\text { contr } \\
\text { ol }\end{array}$ & 2 & 3 & 4 & 5 & 6 & 7 & 8 & 9 \\
\hline \multicolumn{2}{|c|}{ Salinity rate , \% } & 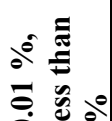 & $\frac{1}{0}$ & $\frac{0^{0}}{i}$ & $\underset{i}{\stackrel{0}{i}}$ & $\begin{array}{r}\stackrel{0}{\circ} \\
\stackrel{0}{\Xi} \\
\Xi\end{array}$ & $\stackrel{1}{m} \stackrel{m}{0}_{0}^{0}$ & $\stackrel{1}{=}$ & $\stackrel{1}{1}$ & : \\
\hline \multicolumn{2}{|c|}{ Name of varieties } & O & & $\ddot{\bar{u}}$ & $\bar{U}$ & 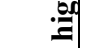 & & & & $\Xi$ \\
\hline 1 & Nukus-2 St & 51.4 & 47.1 & 41.8 & 30.9 & 24.3 & 48.0 & 42.3 & 32.3 & 25.7 \\
\hline 2 & Sanam & 49.6 & 44.9 & 37.3 & 29.4 & 18.5 & 45.1 & 38.7 & 31.0 & 19.9 \\
\hline 3 & Gulzor & 49.4 & 44.5 & 37.0 & 17.7 & 7.6 & 45.0 & 37.8 & 18.1 & 8.3 \\
\hline 4 & Jaykhun & 50.1 & 48.4 & 38.3 & 16.1 & 4.3 & 48.6 & 39.0 & 17.3 & 0.0 \\
\hline 5 & Arpa-sholi & 46.4 & 41.1 & 35.4 & 13.8 & 0.0 & 43.0 & 36.7 & 14.2 & 0.0 \\
\hline 6 & Nukus -70 & 51.1 & 46.3 & 38.9 & 17.2 & 8.2 & 47.1 & 40.0 & 18.0 & 12.7 \\
\hline 7 & Navbahor & 50.6 & 48.8 & 44.8 & 34.9 & 32.9 & 49.1 & 46.3 & 38.0 & 33.8 \\
\hline 8 & Guljahon & 50.9 & 47.3 & 41.0 & 17.5 & 7.9 & 48.0 & 42.1 & 18.9 & 9.0 \\
\hline 9 & Sitora & 48.5 & 45.7 & 37.2 & 14.0 & 5.6 & 46.2 & 37.9 & 15.3 & 6.0 \\
\hline 10 & Sharma (Rossiya) & 50.1 & 47.3 & 40.4 & 15.3 & 9.7 & 48.7 & 41.0 & 17.8 & 12.3 \\
\hline 11 & $\begin{array}{c}\text { Novator } \\
\text { (Rossiya) }\end{array}$ & 47.3 & 41.5 & 33.7 & 10.1 & 0.0 & 42.1 & 34.3 & 11.0 & 0.0 \\
\hline 12 & Avangart St & 50.2 & 45.4 & 30.2 & 23.4 & 0.0 & 46.0 & 35.0 & 26.2 & 0.0 \\
\hline 13 & Iskandar & 51.5 & 46.1 & 40.3 & 25.6 & 11.7 & 47.3 & 41.5 & 26.9 & 15.0 \\
\hline 14 & Ilgor & 48.1 & 44.2 & 39.4 & 23.8 & 0.0 & 45.0 & 43.0 & 26.7 & 0.0 \\
\hline 15 & Akhmadsholi & 47.3 & 41.8 & 35.5 & 21.6 & 0.0 & 42.3 & 36.3 & 22.1 & 0.0 \\
\hline 16 & Tursunboy & 45.8 & 42.9 & 35.9 & 18.3 & 0.0 & 43.2 & 36.4 & 20.0 & 0.0 \\
\hline 17 & Istiqbol & 44.3 & 43.1 & 36.8 & 20.1 & 0.0 & 44.4 & 37.5 & 21.3 & 0.0 \\
\hline 18 & Tolmas & 43.7 & 41.4 & 33.2 & 17.8 & 0.0 & 42.1 & 34.0 & 18.5 & 0.0 \\
\hline 19 & Tantana & 43.2 & 41.8 & 36.0 & 18.3 & 0.0 & 42.2 & 36.8 & 19.0 & 0.0 \\
\hline 20 & Uzros 7-13 St & 51.3 & 45.3 & 26.4 & 13.4 & 0.0 & 46.9 & 30.0 & 25.1 & 0.0 \\
\hline 21 & Lazurny & 48.1 & 45.9 & 36.7 & 23.0 & 12.3 & 46.0 & 41.3 & 26.7 & 17.1 \\
\hline 22 & Mustaqillik & 52.9 & 45.7 & 35.1 & 12.4 & 0.0 & 46.8 & 36.0 & 15.3 & 0.0 \\
\hline 23 & Marvarid & 49.4 & 45.4 & 31.8 & 11.9 & 0.0 & 45.9 & 32.4 & 12.7 & 0.0 \\
\hline 24 & Tarona & 50.8 & 47.2 & 33.1 & 14.1 & 0.0 & 48.7 & 34.8 & 14.0 & 0.0 \\
\hline 25 & Istiqlol & 46.2 & 41.8 & 30.4 & 11.6 & 0.0 & 42.1 & 31.1 & 13.0 & 0.0 \\
\hline & $\mathrm{EFK}_{05} \%$ & 3.2 & 3.6 & 3.9 & 4.1 & 4.7 & 3.1 & 3.8 & 4.2 & 4.5 \\
\hline
\end{tabular}


According to the recommendation of the Uzbek Rice Research Institute (2009), rice varieties were grown at a rate of 5 million tons per hectare. The effect of saline soils on the degree of germination, seedling thickness and survival of plants until the harvest was studied. In the first variant $\left(\mathrm{Cl}\right.$ ion less than $0,01 \%$ in the composition of soils, $\mathrm{SO}_{4}$ ion less than $0.3 \%$ ), the number of seedlings in the $1 \mathrm{~m}^{2}$ area during the germination period of plants was 236,5-248,0 pieces in the early maturing varieties "Nukus-2", "Navahor", "Sanam", and the germination rate of the seeds was 47.3-49.6\%. Furthermore, before the harvest the number of seedlings per $1 \mathrm{~m}^{2}$ was $180.8-184.9$, accounted for $74.2-76.4 \%$ of seed germination. The number of seedlings in the period of germination, especially in medium-ripe varieties as "Avangard", "Iskandar", "Ilgor", was 236.0-248.5 pieces and the germination of seeds was $47.2-49.7 \%$. However, before the harvest the number of seedlings was 176.3-185.1, accounted for 73.-74.7\% of seed germination rate. The number of seedlings in the control was lower by $8-21$ pieces in the germination period, and the rate of seed germination was lower by $1.6-4.2 \%$ than in the first variant. Before the harvest, it was lower by $12.8-26.3$ pieces in seedlings, and the germination was lower by $2.2-4.8 \%$.

The results of the experiment depicted that the number of seedlings in $1 \mathrm{~m}^{2}$ in the third variant with average saline $\mathrm{Cl}$ ion $0.03-0.1 \%$ was 175 , and the germination rate of seeds was $35.0 \%$. Whereas in the variant seven with average saline $\mathrm{SO}_{4}$ ion $1.0-2.0 \%$, the number of seedlings was 222.5 and the germination rate was 45.1. In early ripening varieties, before the harvest, the seedlings were 119 , accounted for $29.3 \%$ of germination in the third variant, and in the variant seven, it was 225.7, and the germination rate of the seeds was $42.1 \%$. In the medium ripening varieties, the number of seedlings in the germination period was 124.1 and the germination rate was $29.3 \%$ in the variant three. The figures were 210.5 and $42.1 \%$ in the variant seven.

The number of seedlings per $1 \mathrm{~m}^{2}$ during the germination period in the 5 th variant with very strong salinity above $0.2 \%$ with soil $\mathrm{Cl}$ ion and the 9 th with very strong salinity above $3.0 \%$ with $\mathrm{SO}_{4}$ ion were 87.0 and 161.5 , accounted for $17.4-32.3 \%$ of germination rate, respectively. In these variants, the number of seedlings before the harvest was 54.9 and 103.4 for the variant five and nine, and their germination rate of the seeds was $60.3 \%$ and $66.4 \%$, correspondingly. Of the medium-ripe varieties, only the Iskandar variety yielded 55.0 and 71.0 pieces, 11.0 and $14.2 \%$, and before the harvest, the number of seedlings was 37.1 and 48.5 and the germination rate was 67.4 and $68.3 \%$ for the variant five and nine. Of the late ripening varieties, only "Lazurny" had 78.0 units, $15.6 \%$ in the variant five, and in the variant nine, it was 56.1 units, $71.9 \%$ before germination in sulfate salinity (Table 3 ). 
Table 3. Influence of salinity on rice field germination, seedling thickness and storage level of rice varieties seeds (2009-2011).

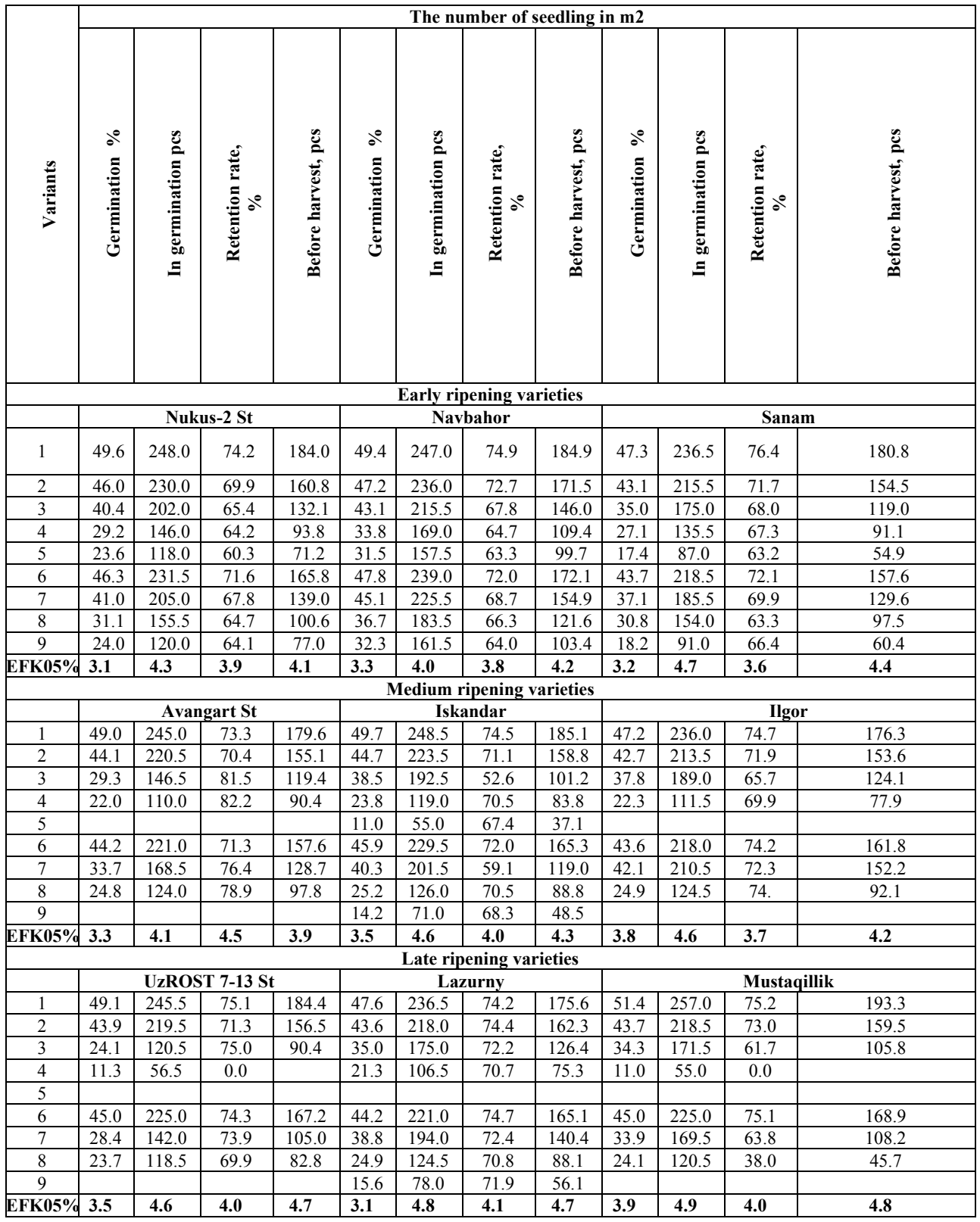

EFK $_{05}$ average 4 


\section{Conclusions}

It was found that fertility of the rice variety in unsalted water $\mathrm{Cl}$ ion was less than $0.01 \%$, $\mathrm{SO}_{4}$ ion was less than $0.3 \%$. In the first variant, the germination rate of seeds of all rice varieties was $94.8-96.7 \%$. In the second variant, where the weakly saline $\mathrm{Cl}$ ion in the experiment was $0.01-0.03 \%$, the germination rate of seeds was $83.4-94.6 \%$ in early ripening rice varieties, such as Nukus-2 St, Sanam, Guljahon, Sharma (Russia) and "Navbahor". However, the middle-aged "Avangard St", "Iskandar", "Ilgor", "Istiqbol", "Tantana" and other varieties were accounted for 84.1-90.3\%, and the late-ripening "Uzros 7-13 St", "Lazurnyy", "Mustaqillik" and "Tarona" had $84.3-90.8 \%$ of germination rate.

In the experiment, in strongly saline soils, in the 4th variant with $\mathrm{Cl}$ ion $0.1-0.2 \%$, the germination rate was $10.1-34.9 \%$ in early ripening varieties of rice, $17.8-25.6 \%$ in medium ripening varieties, $11.6-23.0 \%$ in late ripening varieties. However, in the 5 th variant of the very strongly saline experiment, where the $\mathrm{Cl}$ ion content in the soil was higher than $2.0 \%$, the seed germination in early ripening varieties of rice was $0.0-32.9 \%, 0.0-11.7 \%$ and $0-12.3 \%$ in middle ripening, and in late ripening varieties, respectively.

In the first variant $\left(\mathrm{Cl}\right.$ ion less than $0.01 \%$ in the composition of soils, $\mathrm{SO}_{4}$ ion less than $0.3 \%$ ), the number of seedlings in the $1 \mathrm{~m}^{2}$ area during the germination period of plants was $236,5-248,0$ pieces in the early maturing varieties "Nukus-2", "Navahor", "Sanam", and the germination rate of the seeds was 47.3-49.6\%. Furthermore, before the harvest the number of seedlings per $1 \mathrm{~m}^{2}$ was $180.8-184.9$, accounted for $74.2-76.4 \%$ of seed germination.

\section{References}

1. N. Teshaev, B. Mamadaliyev, A. Ibragimov, S. Khasanov, InterCarto. InterGIS, 26(3), 324-333 (2020)

2. M. Kamran, A. Parveen, S. Ahmar, Z. Malik, S. Hussain, M. Chattha, J. Chen, International journal of molecular sciences, 21, 1 (2020)

3. S. Krishnamurthy, P. Pundir, P., A. Warraich, S. Rathor, B. Lokeshkumar, N. Singh, P. Sharma, Frontiers in plant science, 11 (2020)

4. S. Isaev, S. Khasanov, Y. Ashirov, T. Karabaeva, A. Gofirov, In E3S Web of Conferences, 244, 02012 (2021)

5. S. Isaev, S. Khasanov, Y. Ashirov, A. Gofirov, T. Karabaeva, In E3S Web of Conferences, 244, 02047 (2021)

6. R. Tillaev, B. Kadyrov, Notification of agricultural science of Uzbekistan, 1, 63 (2016)

7. Y. Peng, F. Li, N. Xu, R. Kulmatov, K. Gao, G. Wang, Y. Zhang, Y. Qiao, Y. Li, H. Yang, S. Hao, Q. Li, S. Khasanov, Chinese Journal of Eco-Agriculture, 29(2), 312-324 (2021)

8. R. Kulmatov, A. Taylakov, S. Khasanov, Environmental Science and Pollution Research, 28(10), 12245-12255 (2021)

9. I. Aslanov, S. Khasanov, Y. Khudaybergenov, M. Groll, Ch. Opp, F. Li, E. Ramirez Del-Valle, In E3S Web of Conferences, 227, 02005 (2021)

10. Q. Li, Y. Zhou, M. Xiong, X. Ren, L. Han, J. Wang, Q. Liu, Plant Science, 293 (2020)

11. R. Mouhamad, M. Alabboud, In Plant Stress Physiology, 10 (2020)

12. A. Jumanov, S. Khasanov, A. Tabayev, G. Goziev, U. Uzbekov, E. Malikov, In IOP Conference Series: Earth and Environmental Science, 614(1), 012150 (2020) 
13. A. Radanielson, D. Gaydon, T. Li, O. Angeles, C. Roth, European Journal of Agronomy, 100 (2018) 